\title{
Evaluation of Tumour Necrosis Factor Alpha, Interleukin-2 Soluble Receptor, Nitric Oxide Metabolites, and Lipids as Inflammatory Markers in Type 2 Diabetes Mellitus
}

\author{
Flávia Ozorio Pereira, ${ }^{1}$ Tânia Silvia Frode, ${ }^{2}$ and Yara Santos Medeiros ${ }^{1,3}$ \\ ${ }^{1}$ Diabetes Unit, Governador Celso Ramos Hospital, 88020-30 Florianópolis, Santa Catarina, Brazil \\ ${ }^{2}$ Department of Clinical Analysis, Sciences, and Health Center, Federal University of Santa Catarina, 88040-970 Florianópolis, \\ Santa Catarina, Brazil \\ ${ }^{3}$ Department of Pharmacology, Center of Biological Sciences, Federal University of Santa Catarina, 88049-900 Florianópolis, \\ Santa Catarina, Brazil
}

Received 25 August 2005; Accepted 13 October 2005

\begin{abstract}
This study compared the results of tumour necrosis factor alpha (TNF- $\alpha$ ), interleukin-2 soluble receptor (sIL-2R), nitric oxide metabolites $\left(\mathrm{NO}^{x}\right)$, C-reactive protein (CRP), and lipids (total cholesterol, high-density lipoprotein (HDL-cholesterol), lowdensity lipoprotein (LDL-cholesterol), and triglycerides) between control group (nondiabetic subjects) and overweight type 2 DM subjects. To restrict the influence of variables that could interfere in the interpretation of data, subjects with obesity and/or acute or chronic inflammatory disease, haemoglobinopathies, recent use of antibiotics, antiinflammatory drugs, and trauma were excluded. Type $2 \mathrm{DM}$ patients $\left(n=39\right.$; age $53.3 \pm 9.0$ years; median glycated haemoglobin $\left.\mathrm{A}_{1 c}<8 \%\right)$ presented higher levels of TNF- $\alpha$, triglycerides $(P<.01), \mathrm{NO}^{x}$ and sIL-2R $(P<.05)$ than control group $(n=28$; age $39.7 \pm 14.1$ years $)$. CRP, LDL-cholesterol, total cholesterol, and HDL-cholesterol did not differ among groups. Diabetic women $(n=21)$ had higher levels of TNF- $\alpha$, total cholesterol, LDL-cholesterol, and HDL-cholesterol than diabetic men $(n=18)(P<.05)$, but there were no differences among sexes in the control group. This study indicates that increased level of proinflammatory markers occurs in type $2 \mathrm{DM}$ even in the absence of obesity and marked hyperglycaemia, confirming that the inflammation course of the atherosclerotic process is more severe in diabetic patients than in nondiabetic subjects.
\end{abstract}

Copyright (c) 2006 Flávia Ozorio Pereira et al. This is an open access article distributed under the Creative Commons Attribution License, which permits unrestricted use, distribution, and reproduction in any medium, provided the original work is properly cited.

\section{INTRODUCTION}

Type 2 diabetes mellitus (DM) is associated with an atherogenic status that is related to the presence of a vascular lowgrade inflammation. However, the presence of other risk factors, besides diabetes, limits the analysis of the diabetic state per se in the development of the macrovascular complications. According to the United Kingdom Prospective Diabetes Study (UKPDS) Group [1], the cardiovascular risk in this group is significantly increased when smoking, obesity, hypertension, and dyslipidemia are present. Since type 2 DM has both elevated morbidity and mortality ratios, it is now classified within the high-risk category for developing a cardiovascular event in a similar manner as a nondiabetic person with an established macrovascular complication [2].

Considering that inflammatory markers such as cytokines and C-reactive protein (CRP), besides lipid levels, may be raised several years before a major cardiovascular event, the aim of this study was to evaluate the serum levels of tumour necrosis factor (TNF- $\alpha$ ), the soluble interleukin-2 receptor (sIL-2R), nitric oxide metabolites $\left(\mathrm{NO}^{x}\right)$, CRP, and lipids (total cholesterol, high-density lipoprotein (HDLcholesterol), low-density lipoprotein (LDL-cholesterol), and triglycerides) among type 2 diabetic and nondiabetic subjects. Since it is well known that type $2 \mathrm{DM}$ subjects have multiple risk factors that potentiate each other, we limit our study to diabetic individuals with body mass index (BMI) less than 30 and glycated haemoglobin $\left(\mathrm{HbA}_{1 c}\right)$ bellow $8 \%$ [3].

\section{SUBJECTS AND METHODS}

\section{Subjects}

The studied groups included 40 outpatients with type $2 \mathrm{DM}$ (18 males and 22 females; ages (mean \pm SD) $54.2 \pm 9.2$ years) 
and 28 healthy volunteers as a control group (19 males and 9 females; ages $39.7 \pm 14.1$ years). Diabetic patients were diagnosed according to American Diabetes Association criteria [4]. The control group was selected from subjects that attended the outpatient Endocrine Clinic at Governador Celso Ramos Hospital. All subjects gave written informed consent prior to participation and the study was approved by the Committees on Medical Ethics of both the Federal University of Santa Catarina and Governador Celso Ramos Hospital. The study was carried out in accordance with the regulations and recommendations of the Declaration of Helsinki.

The following exclusion criteria were used for all subjects: acute and chronic inflammatory diseases, haemoglobinopathies, BMI above or equal to 30 and/or less than $19 \mathrm{~kg} / \mathrm{m}^{2}$, not having recently received any antibiotics or anti-inflammatory drugs and no recent history of trauma. In addition, glucose intolerance (fasting or after glucose load) was also used as a criterion for exclusion in the control group. After analysis of either diabetic or nondiabetic records, if each one fulfilled the criteria to participate either in the control or in the diabetic group, an invitation was given by one of the authors.

The following clinical information was obtained from all participants: current medication consumption, presence of macrovascular disease (prior myocardial infarction and stroke history) and family cardiovascular disease, cigarette consumption, and Framingham risk score [2]. All diabetic patients had been screened for retinopathy by an experient ophthalmologist. Hypertension was defined as history of arterial hypertension with or without antihypertensive treatment and/or $>130 \mathrm{~mm} \mathrm{Hg}$ systolic and/or $>80 \mathrm{~mm}$ $\mathrm{Hg}$ diastolic arterial blood pressure (mean of 3-5 repeated blood pressure measurements). Hypercholesterolemia, hypertriglyceridemia, low HDL-cholesterol, and high LDLcholesterol were defined according to recommendations for clinical practice [2]. BMI was calculated as an index of the weight in kilograms divided by the square of the height in meters.

All subjects were asked to discontinue aspirin, if they were using it, at least two weeks prior to blood collections.

\section{Laboratory Procedures}

All subjects were advised to take no medication on the morning before the blood sample was collected. Initially, fasting blood samples were taken between 8:00 and 10:00 a.m. for blood cell analysis and determination of creatinine, $\mathrm{HbA}_{1 c}$, total cholesterol, HDL-cholesterol, and triglycerides. At this time, random (control group) or timed $(24 \mathrm{~h}$, diabetic group) collection of urine to measure microalbuminuria was also requested. In approximately 5-10 days after, fasting blood samples were collected for the measurement of TNF- $\alpha$, sIL-2R, NO ${ }^{x}$, CRP, and erythrocyte sedimentation rate (ESR). Serum aliquots for cytokines and $\mathrm{NO}^{x}$ determinations were stored at $-20^{\circ} \mathrm{C}$.

\section{Analytical determinations}

\section{NO ${ }^{x}$ determinations}

$\mathrm{NO}^{x}$ was measured as its breakdown products nitrite $\left(\mathrm{NO}_{2}{ }^{--}\right)$and nitrate $\left(\mathrm{NO}_{3}{ }^{-}\right)$using the Griess method [5-7]. On the day of the experiments, samples were thawed to room temperature and deproteinized by the addition of $6 \mathrm{mM}$ sodium hydroxide and .6\% of zinc sulphate. Afterwards, $250 \mu \mathrm{L}$ of sample was diluted in $30 \mu \mathrm{L}$ ammonium formate, $30 \mu \mathrm{L}$ of hydrated disodium hydrogen phosphate-12, and $30 \mu \mathrm{L}$ of Escherichia coli (EC ATCC 25922: diluted (1:10) in PBS, $\mathrm{pH}=7.6$ ), and then the mixture was incubated for $2 \mathrm{~h}$ at $37^{\circ} \mathrm{C}$. After centrifugation at $50 \mathrm{xg}$ for 5 minutes, $250 \mu \mathrm{L}$ of the supernatant was transferred to cuvettes and the same volume of fresh Griess reagent 5\% ((vol./vol.) of hydrated disodium hydrogen phosphate-12, $1 \%$ of sulphanilic acid, and $.1 \%$ of $\mathrm{N}$-(1-naphthyl) ethylenediamine) was added and incubated for 10 minutes at room temperature. The reaction of $\mathrm{NO}_{2}{ }^{--}$with this reagent produces a pink colour, which was quantified by colorimetry at $543 \mathrm{~nm}$ against standards $(0-150 \mu \mathrm{M})$ on a spectrophotometer (Hitachi U2001, Model 121-0031, USA).

\section{TNF- $\alpha$ and sIL-2R determinations}

On the day of the measurements, samples were thawed to room temperature. Both TNF- $\alpha$ and sIL-2R were measured by enzyme-linked immunosorbent assay (Boehringer Mannheim Biochemical, Ind, USA) methodologies. Ranges of the values detected by these assays were TNF- $\alpha$, 5$1000 \mathrm{pg} / \mathrm{mL}$; and sIL-2R, 50-100 pmol/L. The intra- and interassay coefficients of variation were $4.6-6.7 \%$ and $6.3-$ $5.3 \%$, respectively, sensitivities of 1.2 and $20.0 \mathrm{pg} / \mathrm{mL}$. The principle of these tests is based on the two-step sandwich technique. Briefly, sample aliquots and standards $(20 \mu \mathrm{L})$ of each assay were transferred to the wells of a microtitre plate and incubated at room temperature $(4 \mathrm{~h})$. Then, the samples were washed three times with washing solution (composition: $\mathrm{NaCl}, 137 \mathrm{mM}$; KCl, $2 \mathrm{mM}$; and phosphate, $10 \mathrm{mM}$; $\mathrm{pH} 7.6$ ), followed by the addition of $200 \mu \mathrm{L}$ of substrate solution to the wells. The microtitre plate was then protected from light and maintained at room temperature (20$30 \mathrm{~min}$ ). The reaction was stopped by adding $50 \mu \mathrm{L}$ of sulphuric acid $(1 \mathrm{~mol} / \mathrm{L})$. One minute later, the concentration of cytokines in each well was determined (Organon, NJ, USA). When indicated by the manufacturer, the procedures were carried out on a shaker (250 r.p.m.).

\section{Other laboratory analysis}

$\mathrm{HbA}_{1 c}$ was determined by high performance liquid chromatography (HPLC, Variant II, Bio Rad, USA, reference range up to $6 \%$ ). CRP was determined by a latex enhanced assay using the BN II apparatus (Dade Behring, Germany, reference range up to $3 \mathrm{mg} / \mathrm{L}$ ). Microalbuminuria was measured by nephelometry (Dade Behring, Germany, reference range up to $.03 \mathrm{mg} / \mathrm{mg}$ creatinine for random specimens 
TABLE 1: Clinical and laboratory characteristics of the studied groups. $n=$ number of subjects, $\mathrm{F}=$ female, $\mathrm{M}=\mathrm{male}, \mathrm{Y} / \mathrm{N}=\mathrm{yes} / \mathrm{no}, \mathrm{NS}=$ not significant, $\mathrm{BMI}=$ body mass index, $\mathrm{SBP}=$ systolic blood pressure, $\mathrm{DBP}=$ diastolic blood pressure, $\mathrm{ESR}=$, erythrocyte sedimentation rate $* *=P<.01, \S=$ mean $\pm \mathrm{SD}, \S \S=$ median (with the 25 th and 75 th centiles-quartiles), $P$ values obtained from either unpaired Student $t$ test, $\lambda^{2}$ test, or Mann-Whitney $U$ test.

\begin{tabular}{|c|c|c|c|}
\hline Characteristics & Diabetic group & Control group & $P$ \\
\hline$n$ & 39 & 28 & - \\
\hline $\operatorname{Sex}(M / F)$ & $18 / 21$ & $19 / 09$ & NS \\
\hline Age (years) $\S$ & $53.3 \pm 9$ & $39.7 \pm 14.1$ & $* *$ \\
\hline BMI $\left(\mathrm{kg} / \mathrm{m}^{2}\right) \S$ & $26.8 \pm 2.6$ & $24.7 \pm 3.2$ & $* *$ \\
\hline Cigarette smoking $(\mathrm{Y} / \mathrm{N})$ & $3 / 36$ & $3 / 25$ & NS \\
\hline $\mathrm{SBP}(\mathrm{mm} \mathrm{Hg}) \S$ & $132.9 \pm 17.2$ & $119.6 \pm 16.2$ & $* *$ \\
\hline DBP (mm Hg) $\S$ & $81.6 \pm 8.5$ & $77.1 \pm 13.6$ & NS \\
\hline Hematocrit (\%) $\S \S$ & $42.2(40.2-44.3)$ & $40.3(38.6-45.2)$ & NS \\
\hline Creatinine $(\mathrm{mg} / \mathrm{dL}) \S$ & $.84 \pm .2$ & $.8 \pm .2$ & NS \\
\hline $\operatorname{ESR}(\mathrm{mm} / \mathrm{h}) \S$ & $11.4 \pm 5$ & $10.8 \pm 5.8$ & NS \\
\hline $\mathrm{HbA}_{1 c}(\%) \S \S$ & $7.0(6.0-8)$ & $5.4(4.9-5.6)$ & $* *$ \\
\hline
\end{tabular}

and up to $30 \mathrm{mg} / 24 \mathrm{~h}$ volume) [8]. Total cholesterol, HDLcholesterol, and triglycerides were measured with standard assays in an ADVIA 1650 apparatus (Bayer, USA). LDLcholesterol was estimated according to the Friedwald formula. The reference values for the lipid profile were according to established guidelines [2].

\section{Statistical analysis}

Data are presented as mean \pm SD if normally distributed and as median (with the 25th and 75th centiles-quartiles) if not normally distributed $\left(\mathrm{HbA}_{1 c}\right.$, hematocrit, microalbuminuria, CRP, $\mathrm{NO}^{x}$, and TNF- $\alpha$ levels). To determine differences between groups, either parametric student's $t$ tests or Mann-Whitney $U$ tests were used. $\lambda^{2}$ test was used to evaluate differences in proportions. Correlations were expressed as Spearman's correlation coefficients. The level of statistical significance was set at $P<.05$.

\section{Results}

The baseline characteristics of the studied participants are presented in Table 1. The groups did not differ in relation to sex, smoking, and nutritional status as indirectly evaluated by creatinine and blood (red and white) cell analysis. Neither group presented clinical or laboratorial (ESR and CRP values) evidence of either acute or chronic inflammatory diseases, except for one diabetic patient whose CRP level was greater than $10 \mathrm{mg} / \mathrm{L}$ and who consequently was excluded from analyses.

Diabetic patients were overweight (mean BMI values = $\left.26.8 \pm 2.6 \mathrm{~kg} / \mathrm{m}^{2}\right)$, whereas the control group presented normal values $\left(\right.$ mean BMI $\left.=24.7 \pm 3.2 \mathrm{~kg} / \mathrm{m}^{2}\right)(P<.01)$. Inasmuch, $\mathrm{HbA}_{1 c}$ levels in diabetic patients were higher than those in the control group $(P<.01)$.

Other characteristics of the diabetic group are depicted in Table 2. Eight (20.5\%) patients had microalbuminuria, while $26(66.6 \%)$ had hypertension. Microvascular complications were detected in 39\% but clinical evidence of macrovascular disease was observed in only $12.1 \%$. All patients received treatment for DM, the majority of them were on monotherapy $(71.8 \%)$ (Table 2 ).

In the control group, three subjects had hypertension but only two were receiving treatment. Microalbuminuria values in random samples were normal (median total protein/creatinine ratio: $.01 \mathrm{mg} / \mathrm{mg}$ of creatinine, $25 \mathrm{th}$ and $75 \mathrm{th}$ centiles-quartiles $=.004$ and $.02 \mathrm{mg} / \mathrm{mg}$ ).

As shown in Table 3, the median values of TNF- $\alpha$, sIL$2 \mathrm{R}, \mathrm{NO}^{x}$, and mean triglyceride concentrations were higher in the diabetic group in comparison to those obtained in the control group $(P<.05)$. The other variables (HDLcholesterol, total cholesterol, and LDL-cholesterol) did not differ between the groups. Furthermore, median values of CRP also did not differ among diabetic and control groups (Table 3). Individual values of CRP were distributed as low $(<1)$, moderate ( 1 to 3$)$, and high ( $>3 \mathrm{mg} / \mathrm{L}$ ) according to Ridker PM [9]. According to this classification, there were no differences within the same subgroup among control and diabetic subjects. However, some subjects of the control group as well as some diabetic patients presented CRP levels higher than $3 \mathrm{mg} / \mathrm{L}$ (Figure 1).

Determinations of 10-year risk of coronary event were done by using Framingham risk score [2]. As expected, only diabetic persons had the high-risk scores (class 1), whereas subjects from control groups were classified among subgroups 2 and 3. In agreement with Framingham risk score, higher increase of CRP levels was observed in class 2 than in class 3 (Figure 2) $(P<.05)$.

In the diabetic group, a positive association was found among CRP levels and triglycerides concentrations $(r=.45)$, whereas a negative association was observed among $\mathrm{NO}^{x}$ values and TNF- $\alpha$ determinations $(r=-.3)$ (Figures 3(a) and 3 (b)). No significant association was found among the studied variables in the control group.

Diabetic women $(n=21)$ presented higher levels of TNF- $\alpha$ (median; 25th and 75th centiles-quartiles $=190$; 
TABLE 2: Baseline clinical characteristics of studied diabetic patients. $n=$ number of subjects, $\S=$ mean and range, $\S \S=$ median (with the 25 th and 75 th centiles-quartiles), $*=$ number of cases. $\dagger=$ treated with metformin, sulphonylurea, or insulin. $\dagger+=$ treated with two or more agents.

\begin{tabular}{lc}
\hline$n$ & 39 \\
Time of disease (years) $\S$ & $7.1(1-17)$ \\
Microalbuminuria (mg/24h) $\S \S$ & $10(6.9-36.9)(8 / 39) *$ \\
Microvascular complications & $15 / 39$ \\
Macrovascular complications (clinical evidence) & $5 / 39$ \\
Diabetes treatment & $39 / 39$ \\
Monotherapy $\dagger$ & $28 / 39$ \\
Therapy combination $\dagger \dagger$ & $11 / 39$ \\
Lipid treatment & $9 / 39$ \\
Hypertension treatment & $26 / 39$ \\
\hline
\end{tabular}

TABLE 3: Serum concentrations of the studied parameters. $n=$ number of subjects, TNF- $\alpha=$ tumour necrosis factor alpha, sIL-2R $=$ soluble interleukin 2 receptor, $\mathrm{NO}^{x}=$ nitric oxide metabolites, $\S=$ median (with the 25 th and 75 th centiles-quartiles), $\S \S=$ mean $\pm \mathrm{SD}$, NS $=$ not significant, $*=P<.05, * *=P<.01, * * *=P<.001$.

\begin{tabular}{|c|c|c|c|}
\hline Parameters & Diabetic patients & Control group & $P$ \\
\hline$n$ & 39 & 28 & - \\
\hline $\mathrm{CRP}(\mathrm{mg} / \mathrm{L}) \S$ & $1.4(.7-2.7)$ & $2.0(.5-4.3)$ & NS \\
\hline TNF- $\alpha(\mathrm{pg} / \mathrm{mL}) \S$ & $100(39-235)$ & $12(6-26.5)$ & $* * *$ \\
\hline sIL-2R $(\mathrm{pmol} / \mathrm{mL}) \S$ & $89.4(74.3-112.8)$ & $74.7(56.0-106.0)$ & $*$ \\
\hline $\mathrm{NO}^{x}(\mu \mathrm{mol} / \mathrm{L}) \S$ & $8.34(6.3-15.2)$ & $6.8(5.1-9.3)$ & $*$ \\
\hline HDL-cholesterol (mg/dL) $\S \S$ & $51.2 \pm 13.4$ & $56.6 \pm 14$ & NS \\
\hline LDL-cholesterol (mg/dL) $\S \S$ & $128.7 \pm 36.8$ & $122.6 \pm 38.7$ & NS \\
\hline Total cholesterol (mg/dL) $\S \S$ & $208.5 \pm 44.5$ & $199 \pm 40.8$ & NS \\
\hline Triglycerides $(\mathrm{mg} / \mathrm{dL}) \S \S$ & $148.5 \pm 59.7$ & $92.9 \pm 43.4$ & $* *$ \\
\hline
\end{tabular}

91-380 pg/mL), total cholesterol (mean \pm SD $=223 \pm$ $49.5 \mathrm{mg} / \mathrm{dL}$ ), LDL-cholesterol (mean $\pm \mathrm{SD}=140 \pm 38.9$ $\mathrm{mg} / \mathrm{dL}$ ), and HDL-cholesterol (mean $\pm \mathrm{SD}=55.8 \pm$ $14.8 \mathrm{mg} / \mathrm{dL})$ in comparison to diabetic men $(n=18$, TNF- $\alpha=70 ; 28-105 \mathrm{pg} / \mathrm{mL}$, total cholesterol $=191.8 \pm$ $31.4 \mathrm{mg} / \mathrm{dL}$, LDL-cholesterol $=117.8 \pm 28.1 \mathrm{mg} / \mathrm{dL}$, and HDL-cholesterol $=45.7 \pm 9 \mathrm{mg} / \mathrm{dL}$ ). On the other hand, no differences among sexes were observed in the control group.

\section{DISCUSSION}

The data from this study demonstrate that TNF- $\alpha$, sIL-2R, $\mathrm{NO}^{x}$, and triglycerides, but not CRP, are increased in this subgroup of diabetic patients. These results confirm reports in the literature that a low-grade inflammation exists in type 2 diabetic patients in spite of the absence of obesity and significant hyperglycaemia. In addition, these results also show that in the diabetic group, the inflammatory markers significantly differ among the sexes, being higher in women in comparison to men.

A relationship between TNF- $\alpha$ and diabetes has been described in several stages of this disease. Thus, increased TNF$\alpha$ levels have been associated with (1) other cytokines and increased risk of developing diabetes [9]; (2) high triglycerides concentrations in metabolic syndrome [10]; and (3) a significant number of both fatal and nonfatal cardiovascular outcomes [11]. In this study, diabetic patients presented elevated levels of TNF- $\alpha$ in spite of being nonobese, but overweight and with median levels of $\mathrm{HbA}_{1 c}$ of $7 \%$ (maximum of $8 \%$ ). In addition, raised serum levels of $\mathrm{NO}^{x}$ and sIL$2 \mathrm{R}$ also were detected in this group. It is reported that increased serum levels of $\mathrm{NO}^{x}$ indirectly reflect the presence of either endothelial dysfunction or vascular injury, including microvascular complications $[12,13]$. Several hypotheses have been raised to explain the increased serum levels of $\mathrm{NO}^{x}$ in diabetic patients. Chiarelli et al [14] reported that the $\mathrm{HbA}_{1 c}$ concentration was significantly and positively related to $\mathrm{NO}_{2}{ }^{--}$plus $\mathrm{NO}_{3}{ }^{-}$serum content, whereas others have suggested that the raised levels of $\mathrm{NO}^{x}$ could reflect the negative feedback with cyclic guanosine- $3^{\prime}, 5^{\prime}$-monophosphate (cGMP) [15] since $\mathrm{NO}^{x}$ interacts with soluble guanylate cyclase, leading to elevation of cGMP concentrations. In this instance, vasodilation would be blunted in diabetic subjects, not because of an inability to produce $\mathrm{NO}^{x}$, but rather due to an inhibition of the action of $\mathrm{NO}^{x}$ presumably secondary to the generation of cGMP which is reported to be low [16]. One cannot discard, however, the possibility that besides the hypothesis of the existence of a defect in the generation of 


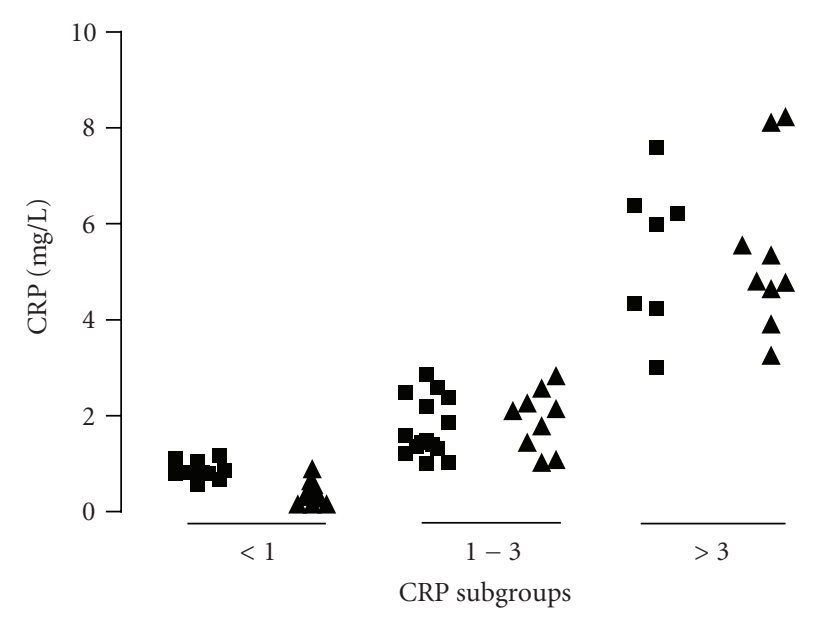

- Diabetic groups

$\Delta$ Control groups

FIGURE 1: Distribution of CRP in diabetic ( $\boldsymbol{\square})$ and control ( $\mathbf{\Delta})$ groups. Data are shown using three simple clinical cut-off points for CRP: less than 1, 1 to 3 , and greater than $3 \mathrm{mg} / \mathrm{L}$.

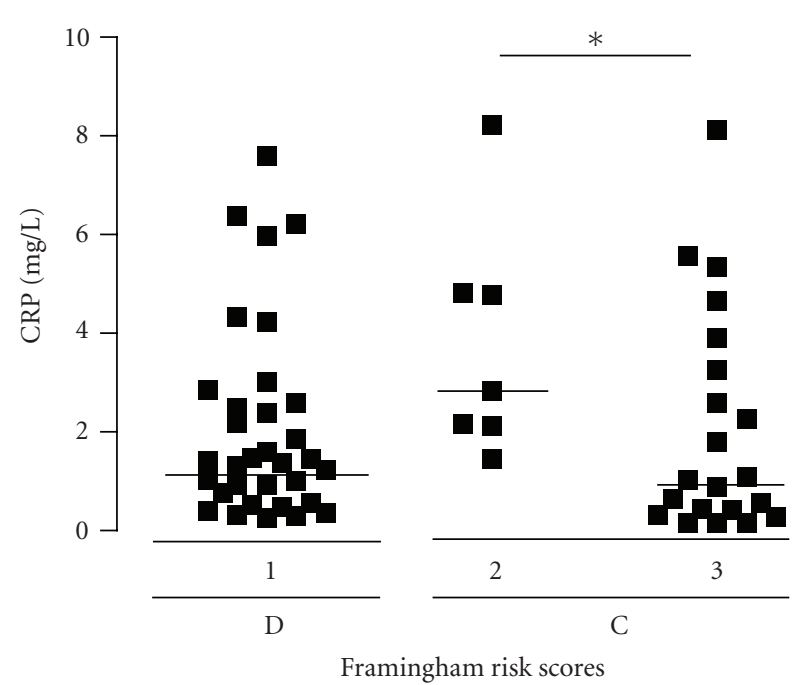

FIgURE 2: Distribution of CRP levels and Framingham risk scores $(1,2$, and 3$)$ in diabetic (D) and control (C) groups. The solid lines represent the median values of each subgroup; $*=P<.05$.

cGMP, other sources of $\mathrm{NO}^{x}$ could be contributing to its serum level via the expression of induced NO-synthase by inflammatory cells (macrophages, neutrophils, and vascular muscle cells, among others). Furthermore, the findings of raised levels of sIL-2R in diabetic patients are in accordance with those reported by Doganay et al [17] and this indicates activation of T lymphocytes [18]. Taken together, these findings suggest that this group of diabetic patients present a low-grade inflammation triggered by the diabetic mellitus state, which is favouring the progression of accelerated atherosclerosis. Within this context, data from the UKPDS have demonstrated that about $50 \%$ of newly diagnosed type 2

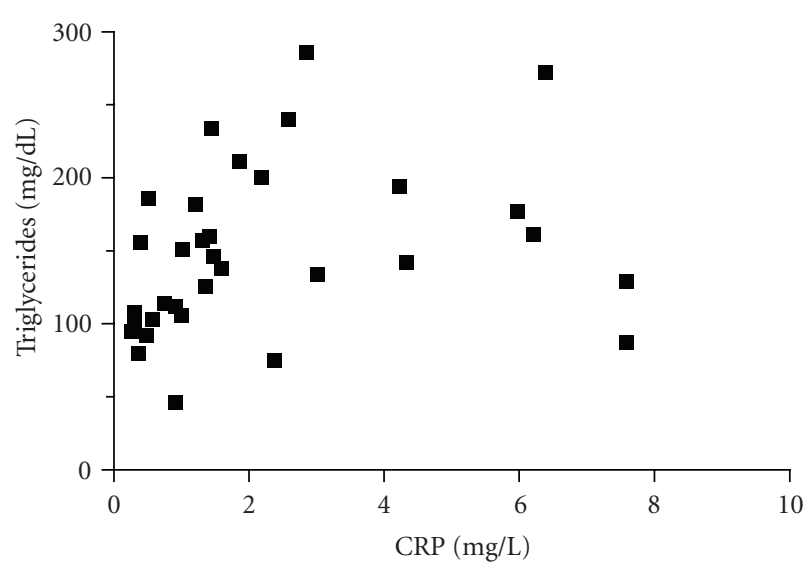

(a)

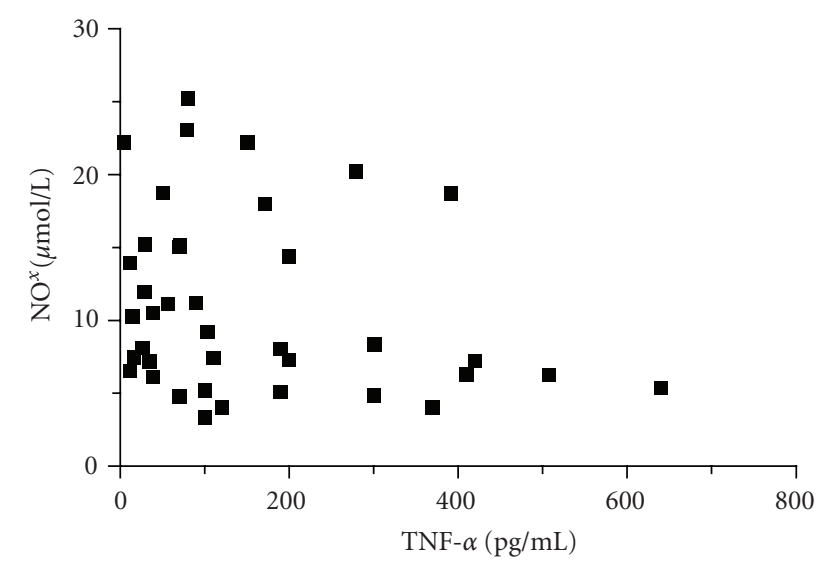

(b)

FIGURE 3: (a) Correlation between the concentrations of CRP and triglycerides in diabetic patients; $r=.45$ and $p<.01$. (b) Correlation between the concentrations of TNF- $\alpha$ and $\mathrm{NO}^{x}$ in the diabetic patients; $r=-.3$ and $p<.05$. Each individual value is represented by a symbol ( $\mathbf{\square}), r=$ Spearman's rank correlation coefficients.

DM present some evidence of cardiovascular complications, [1] confirming data shown by others $[16,19,20]$ that the inflammation course of the atherosclerotic process is more severe in diabetic patients than in nondiabetic subjects. However, in contrast to other clinical studies [21, 22], we do not have a clear explanation of the negative relationship between the serum concentrations of TNF- $\alpha$ and $\mathrm{NO}^{x}$.

In agreement with other studies $[23,24]$, our study found that CRP is not a surrogate marker for cardiovascular disease in diabetic patients, unless either kidney dysfunction or polymorphisms in loci for CRP are present [25]. However, further studies are needed to better evaluate the outcome of the diabetic subgroup that presented high levels of CRP. Recently, Schulze et al [26] reported that high plasma levels of CRP were associated with an increased risk of cardiovascular events among diabetic men, independent of currently established lifestyle risk factors, blood lipids, and glycaemic control. Regarding the present study, one cannot rule out the possibility that the absence of obesity, significant hyperglycaemia, and the normal levels of HDL-cholesterol in 
the diabetic group may have contributed to these results. In addition, the finding that serum levels of both CRP and triglycerides are positively correlated provides a further indication that both variables contribute to the vascular inflammatory process. On the other hand, as it was previously demonstrated, individual analysis of CRP showed that its high levels are related with increased Framingham risk score and is useful in identifying nondiabetic individuals who should be considered for more protective treatment programs $[27,28]$.

A significant finding in the present study was the results in the subgroup of diabetic women. Considering that once cardiovascular disease is present in women, they have a worse outcome than male counterparts, the same statement is valid for diabetic women $[29,30]$. An elevated cardiovascular risk has been recognized in this subgroup in comparison to diabetic men, even in the absence of hypertension, dyslipidemia, and before the menopause [31, 32]. In agreement with these data, the present work found high serum levels of TNF- $\alpha$, total cholesterol, and LDL-cholesterol in diabetic women in comparison to diabetic men.

In conclusion, our study shows that some surrogate markers of cardiovascular inflammation are elevated in diabetic patients. Taken together, these data support the opinion that diabetic patients present a high risk for cardiovascular disease and need early aggressive intervention.

\section{REFERENCES}

[1] United Kingdom Prospective Diabetes Study (UKPDS) Group: Intensive blood-glucose control with sulphonylureas or insulin compared with conventional treatment and risk of complications in patients with type 2 diabetes (UKPDS 33). Lancet. 1998;352(9131):837-853.

[2] Executive Summary of the Third Report of the National Cholesterol Education Program (NCEP). Expert panel on detection, evaluation, and treatment of high blood cholesterol in adults (adult treatment panel III). JAMA: The Journal of the American Medical Association. 2001;285(19):2486-2497.

[3] The Diabetes Control and Complications Trial Research Group: The effect of intensive treatment of diabetes on the development and progression of long-term complications in insulin-dependent diabetes mellitus. The New England Journal of Medicine. 1993;329(14):977-986.

[4] American Diabetes Association (ADA). Diagnosis and classification of diabetes mellitus. Diabetes Care. 2004;27(suppl 1):S5-S10.

[5] Green LC, Wagner DA, Glogowski J, Skipper PL, Wishnok JS, Tannenbaum SR. Analysis of nitrate, nitrite, and [15N]nitrate in biological fluids. Analytical Biochemistry. 1982;126(1):131138.

[6] Di Rosa M, Ialenti A, Ianaro A, Sautebin L. Interaction between nitric oxide and cyclooxygenase pathways. Prostaglandins, Leukotrienes, and Essential Fatty Acids. 1996;54 (4):229-238.

[7] Ellis G, Adatia I, Yazdanpanah M, Makela SK. Nitrite and nitrate analyses: a clinical biochemistry perspective. Clinical Biochemistry. 1998;31(4):195-220.

[8] Molitch ME, DeFronzo RA, Franz MJ, et al. Nephropathy in diabetes. Diabetes Care. 2004;27(suppl 1):S79-S83.
[9] Ridker PM. Clinical application of C-reactive protein for cardiovascular disease detection and prevention. Circulation. 2003;107(3):363-369.

[10] Jonkers IJ, Mohrschladt MF, Westendorp RG, van der Laarse A, Smelt AH. Severe hypertriglyceridemia with insulin resistance is associated with systemic inflammation: reversal with bezafibrate therapy in a randomized controlled trial. The American Journal of Medicine. 2002;112(4):275-280.

[11] Ridker PM, Rifai N, Pfeffer M, Sacks F, Lepage S, Braunwald E. Elevation of tumor necrosis factor- $\alpha$ and increased risk of recurrent coronary events after myocardial infarction. Circulation. 2000;101(18):2149-2153.

[12] Matata BM, Galinanes M. Effect of diabetes on nitric oxide metabolism during cardiac surgery. Diabetes. 2001;50(11):2603-2610.

[13] Ozden S, Tatlipinar S, Bicer N, et al. Basal serum nitric oxide levels in patients with type 2 diabetes mellitus and different stages of retinopathy. Canadian Journal of Ophthalmology. 2003;38(5):393-396.

[14] Chiarelli F, Cipollone F, Romano F, et al. Increased circulating nitric oxide in young patients with type 1 diabetes and persistent microalbuminuria: relation to glomerular hyperfiltration. Diabetes. 2000;49(7):1258-1263.

[15] Aydin A, Orhan H, Sayal A, Ozata M, Sahin G, Isimer A. Oxidative stress and nitric oxide related parameters in type II diabetes mellitus: effects of glycemic control. Clinical Biochemistry. 2001;34(1):65-70.

[16] Piatti PM, Monti LD, Zavaroni I, et al. Alterations in nitric oxide/cyclic-GMP pathway in nondiabetic siblings of patients with type 2 diabetes. The Journal of Clinical Endocrinology and Metabolism. 2000;85(7):2416-2420.

[17] Doganay S, Evereklioglu C, Er H, et al. Comparison of serum NO, TNF-alpha, IL-1beta, sIL-2R, IL-6 and IL-8 levels with grades of retinopathy in patients with diabetes mellitus. Eye. 2002;16(2):163-170.

[18] Castillo FM, Romero TA, Estévez J, et al. Concentrations of cytokines, soluble interleukin-2 receptor, and soluble CD30 in sera of patients with hepatitis B virus infection during acute and convalescent phases. Clinical and Diagnostic Laboratory Immunology. 2002;9(6):1372-1375.

[19] Coutinho M, Gerstein HC, Wang Y, Yusuf S. The relationship between glucose and incident cardiovascular events. A metaregression analysis of published data from 20 studies of 95,783 individuals followed for 12.4 years. Diabetes Care. 1999;22(2):233-240.

[20] Haffner SM, Lehto S, Ronnemaa T, Pyorala K, Laakso M. Mortality from coronary heart disease in subjects with type 2 diabetes and in nondiabetic subjects with and without prior myocardial infarction. The New England Journal of Medicine. 1998;339(4):229-234.

[21] Nakae H, Endo S, Kikuchi M, et al. Nitrite/nitrate (NOx) levels and hemodynamics during septic shock. Surgery Today. 2000;30(8):683-688.

[22] Gustafsson I, Brendorp B, Seibaek M, et al. Influence of diabetes and diabetes-gender interaction on the risk of death in patients hospitalized with congestive heart failure. Journal of the American College of Cardiology. 2004;43(5):771-777.

[23] Calles-Escandon J, Cipolla M. Diabetes and endothelial dysfunction: a clinical perspective. Endocrine Reviews. 2001;22(1):36-52.

[24] Danesh J, Wheeler JG, Hirschfield GM, et al. C-reactive protein and other circulating markers of inflammation in the prediction of coronary heart disease. The New England Journal of Medicine. 2004;350(14):1387-1397. 
[25] Wolford JK, Gruber JD, Ossowski VM, et al. A C-reactive protein promoter polymorphism is associated with type 2 diabetes mellitus in Pima Indians. Molecular Genetics and Metabolism. 2003;78(2):136-144.

[26] Schulze MB, Rimm EB, Li T, Rifai N, Stampfer MJ, Hu FB. C-reactive protein and incident cardiovascular events among men with diabetes. Diabetes Care. 2004;27(4):889-894.

[27] Ridker PM, Rifai N, Rose L, Buring JE, Cook NR. Comparison of C-reactive protein and low-density lipoprotein cholesterol levels in the prediction of first cardiovascular events. The New England Journal of Medicine. 2002;347(20):1557-1565.

[28] Hansson GK. Inflammation, atherosclerosis, and coronary artery disease. The New England Journal of Medicine. 2005;352(16):1685-1695.

[29] Norris CM, Ghali WA, Galbraith PD, Graham MM, Jensen LA, Knudtson ML. Women with coronary artery disease report worse health-related quality of life outcomes compared to men. Health and Quality of Life Outcomes. 2004;2(1):21.

[30] King KM, Ghali WA, Faris PD, et al. Sex differences in outcomes after cardiac catheterization: effect modification by treatment strategy and time. JAMA: The Journal of the American Medical Association. 2004;291(10):1220-1225.

[31] Laakso M, Lehto S. Epidemiology of macrovascular disease in diabetes. Diabetes Reviews. 1997;5(4):294-315.

[32] Smitherman TC, Reis SE. Heart disease in women with diabetes. Diabetes Spectrum. 1997;10(3):207-215. 


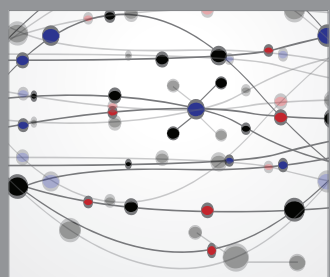

The Scientific World Journal
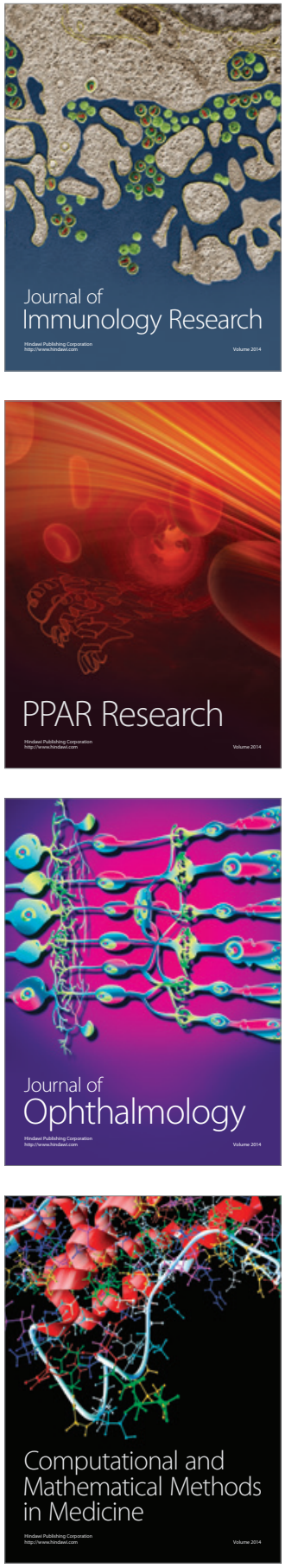

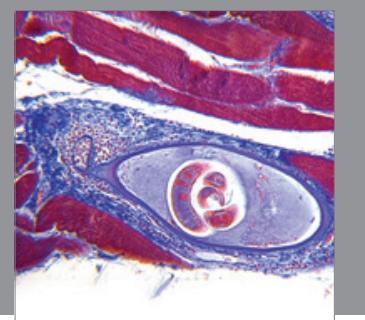

Gastroenterology

Research and Practice
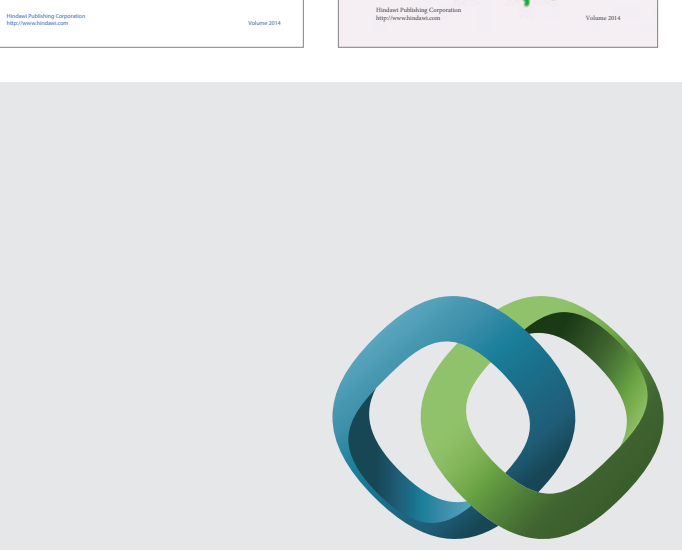

\section{Hindawi}

Submit your manuscripts at

http://www.hindawi.com
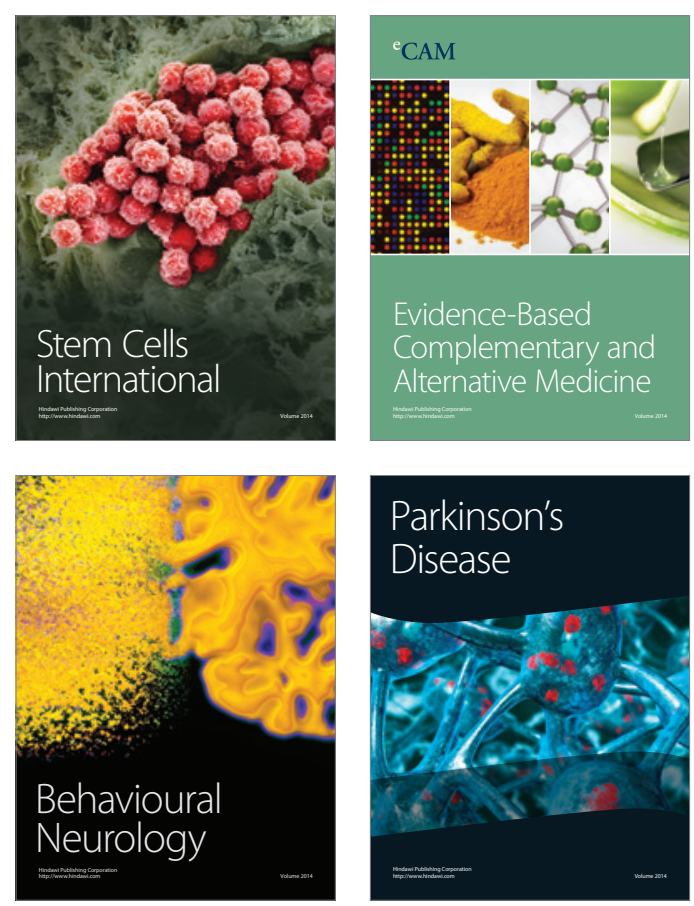

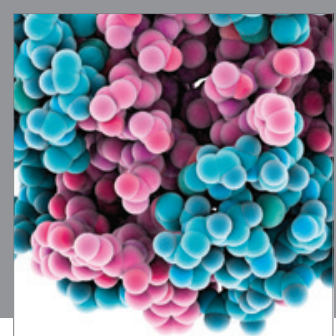

Journal of
Diabetes Research

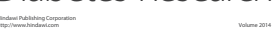

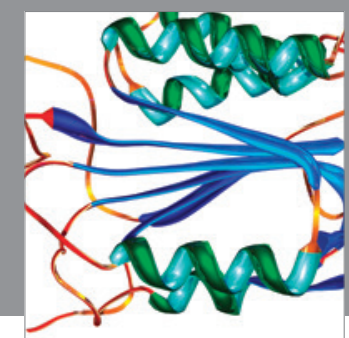

Disease Markers
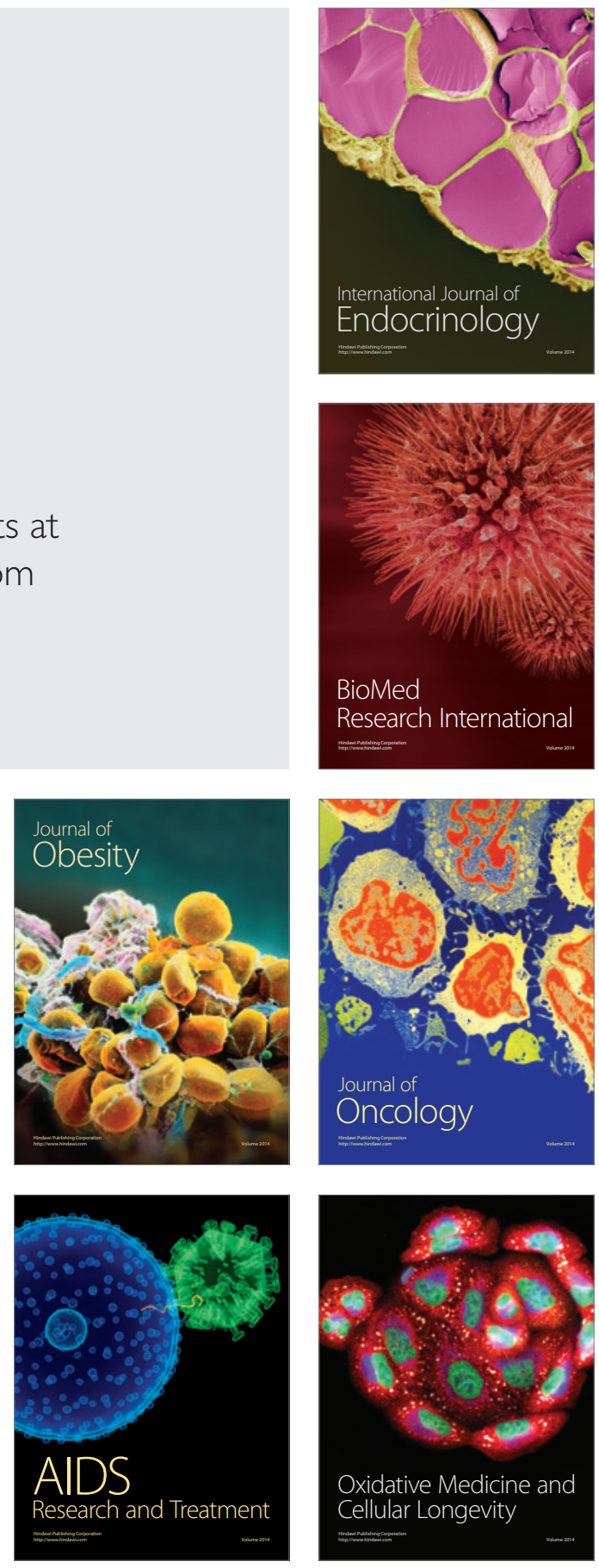